\title{
Proceeding
}

Supplementary Issue: Autumn Conferences of Sports Science. Costa Blanca Sports Science Events, 18-19 December 2020. Alicante, Spain.

\section{Somatotype and body composition as an indicator to determine the role of performance in the men's basketball team in the youth team Del Campo School}

\author{
CARLOS EDUARDO MENÉNDEZ-AMADOR ${ }^{1} \unlhd$, RAÚL ORLANDO FIGUEROA-SORIANO², RAUL \\ ANTONIO GAITAN-AMADOR ${ }^{3}$ \\ ${ }^{1}$ Department of Physical Culture, Faculty of Humanities and Arts, National Autonomous University of \\ Honduras, Tegucigalpa, Honduras \\ 2 University Management Board, National Autonomous University of Honduras, Tegucigalpa, Honduras \\ ${ }^{3}$ Danlí Regional University Centre, National Autonomous University of Honduras, Tegucigalpa, Honduras
}

\begin{abstract}
The following descriptive study, with a quantitative approach that allowed to offer pertinent information to the somatotype and the body composition of the basketball player, in such a way that it allows a survey of both the player's profile in a general way and specifically, according to the role that plays in the team and would contribute to the diagnosis of the team in terms of planning workloads in training. The sample is of a nonprobabilistic type directed, the selection procedure by quota intentionally, made up of 12 students who are part of the men's basketball team at Del Campo of Tegucigalpa school. The Carter method for somatoplotting and the Parizkova and Buzkova method were applied, where the results were favourable considering that the tests offer useful information such as the presence of five players with a percentage of body fat (KG GRSA) above from the mean with respect to age, the rest with favourable levels of $\%$ ACM for basketball practice.

Keywords: Somatotype; Body composition; Anthropometry; Basketball.

\section{Cite this article as:}

Menéndez-Amador, C.E., Figueroa-Soriano, R.O., \& Gaitan-Amador, R.A. (2021). Somatotype and body composition as an indicator to determine the role of performance in the men's basketball team in the youth team Del Campo School. Journal of Human Sport and Exercise, 16(2proc), S801-S810. doi:https://doi.org/10.14198/ihse.2021.16.Proc2.66

Corresponding author. Departamento de Cultura Física, Facultad de Humanidades y Artes, Universidad Nacional Autónoma de Honduras, Tegucigalpa, Honduras. https://orcid.org/0000-0002-2368-9491

E-mail: carlos.menendez@unah.edu.hn

Abstract submitted to: Summer Conferences of Sports Science. Costa Blanca Sports Science Events, 25-26 September 2020. Alicante, Spain.

JOURNAL OF HUMAN SPORT \& EXERCISE ISSN 1988-5202

(c) Faculty of Education. University of Alicante

doi:10.14198/jhse.2021.16.Proc2.66
\end{abstract}




\section{INTRODUCTION}

This project is of great relevance in its application, at least in this area of knowledge and for the field school. It consists of taking measurements to generate through corresponding formulas the somatotype of the athletes stated and determining their composition. This study will be applied to students who belong to the men's basketball team at La del Campo school and thus determine which somatotype it corresponds to and their body composition.

The field school includes high-performance sports development in various sports, so it is essential to know the somatotype and body composition of the players of the different sports they develop and thus determine the different loads to use to obtain the sports form for the competitions to which they are planned. The basketball team of this youth category institution has not yet carried out a diagnostic study about their somatotype and body composition, which refers to an analysis of this in order to plan their load for competitions.

Among the functions of the field school, the practice of high performance basketball is included, which it attributes to determining the somatotype and body composition of the athletes that make up the team of this sporting discipline and who currently have not done so. Determined for decision making is already for the nutritional part and the application of the load in relation to the sports training process, aspects that are of great importance and that for decision making the components listed above must be known and they therefore they do not have the staff of knowledge and instruments.

The somatotype and body composition are two aspects that attribute a great benefit in the systematic practice of sports training since through the study of these, the loads to be applied and the nutritional aspect to be taken into account in this process can be defined. There are several studies that are currently being carried out on this subject in many countries of the World, Urdampilleta, Martínez-Sanz, Cejuela (2014) Del Campo, Escortell, Sospedra, I., stand out. Norte, Martínez, and Martínez (2016) Gryko, K., Stastny, \& Kopiczko (2019). In Honduras, those registered are very scarce and more in the sports context, but they occur in the field of health, their social relevance can be manifested through this study in the sports area since it is of interest to the institution (UNAH -TEC-Danlí) and the school of the field that we do the analysis to generate data necessary in the process of sports training of young male basketball players. The beneficiaries of this investigation would be the field school and its men's basketball athletes from said institution. The impact of this study is of great magnitude since through the generation of data on the somatotype and body composition in the sport listed, the sample of all athletes from the field school can be enlarged. The research project is quite feasible because we have the appropriate personnel, the instruments and the facility of the field school with all its facilities and human material.

\section{METHODOLOGY}

Somatotype and body composition of field school male basketball athletes is a study that will have a (Quantitative) approach. Well, the inquiry merits it in attention to the use of instruments that generated quantification data and in turn takes into account the theoretical arguments of Hernández (2014), which they argue, that in quantitative studies data collection and analysis is used to generate proposals, aspects that are inserted in this study to be carried out. They argue that this type of study is a symbiosis of theory and practice since it presents applications of research methods, procedures and techniques that will generate quantitative and qualitative data on the physical state to solve a perceived need regarding the object of study to investigate. Emphasizing that these data to be obtained are more quantitative. 
The design to be applied is Non-Experimental Cross-sectional with a descriptive scope without the deliberate manipulation of variables and in which only the phenomena are observed in their natural environment to analyse it and specifically is that in this type of study data are collected in a single moment, in single time. That its purpose is to describe variables and analyse their incidence and interrelate it at a given moment.

\section{Population and sample}

The sample is of a non-probabilistic type directed, the selection procedure by quota intentionally, made up of 12 students who are part of the men's basketball team of the Del Campo school in Tegucigalpa.

\section{Variables and their definition}

Somatotype It is the quantification of the three primary components of the human body that make up the morphology of the individual, expressed in three (3) figures (which represented its primary components and depending on which one predominates, it classified individuals as: Edomorphic, Mesomorphic and Ectomorphic. (Willian Sheldon. 1940).

Body composition is what allows us to assess with good judgment the effects of training on the human organism, since each of the components into which we can divide the total body weight can undergo different variations in its constitution, depending on the type of training developed. (Porta, Galiano, Tejedo1991).

Table 1. Table of Variable X1 and its operational definition.

\begin{tabular}{ll}
\hline Variable X1 & Operational definition \\
\hline (X1) Somatotype & $\begin{array}{l}\text { It will be expressed through the method of Heath and Carter 1967. Where the } \\
\text { regression equations provided by said author were used. }\end{array}$
\end{tabular}

Table 2. Table of Variable X2 and its operational definition.

\begin{tabular}{ll}
\hline Variable X2 & Operational definition \\
\hline (X2) Body composition & The method of Parizkova and Buzkova 1971 will be used. \\
\hline
\end{tabular}

\section{Process}

The Carter method for somatoplotting and the Parizkova and Buzkova method will be applied, taking into account the following measurements:

The anthropometric magnitudes that will be taken in this study are: Height, Weight, Humerus Diameter (right), Femur Diameter (right), Flexed Brachial Circumference (right), Leg Circumference (right), Bicipital Skin Fold, Skin Fold Tricipital, Subscapular Skin Fold, Suprailiac Skin Fold, Leg Skin Fold.

\section{Weight}

It is defined as obtaining the total weight of the subject dressed with the minimum possible clothing, located in the centre of the platform and facing the scale, ensuring that the anthropometric position is maintained without any support.

\section{Height}

It is defined as the maximum length measured from the vertex to the horizontal plane of the base of the stadiometer (altimeter), which occurs when the subject is in an anthropometric position, where the heels, buttocks, back and head should be attached to the under surface of the instrument, the mid-sagittal line should coincide with the midline of the instrument. The mobile part will be slid until it is in contact with the vertex, pressing slightly. 


\section{Humerus diameter}

It is defined as the maximum distance or diameter between the epicondyles of the humerus epiphysis. The subject should be seated with the trunk straight and the head in the Frankfurt plane and the arm to be measured at a right angle to the trunk and the forearm at a right angle to the latter, with the palm of the hand directed towards it. It will be verified that the subject is relaxed and with the legs in the correct position. The ends of the instrument are placed on the epicondyles of the humerus, moving up and down slightly until reaching the maximum diameter.

\section{Diameter of the femur}

It is defined as the distance or maximum diameter that exists between the condyles of the femur. The individual is seated in the correct position, the head in the Frankfurt plane, the lower extremities should be slightly apart to facilitate measurement, and the thighs should form a right angle to the trunk and the legs in the correct position. The ends of the instrument are placed on the epicondyles of the femur, moving up and down slightly until the maximum diameter is reached.

\section{Contracted arm circumference}

It is defined as the maximum perimeter of the arm in the region where the biceps reaches its greatest volume during a maximum contraction. The subject will be placed in a modified anthropometric position, the technician will place the arm to be measured at a right angle with respect to the trunk and the forearm in the same position with respect to the arm and will make a loop without tightening the tape, after this it is requested You perform a maximum contraction of the biceps by placing the tape in the most voluminous area and the reading is made.

\section{Leg circumference}

It is defined as the maximum perimeter of the most voluminous region formed by the calf muscles, when the tape is perpendicular to the axis of the leg. The subject must be in an anthropometric position with the feet approximately $30 \mathrm{~cm}$ apart, the technician will wrap the tape around the leg to be measured with the technique described, covering the most voluminous area formed by the calves. Two (2) loops must be made, repeating and taking the reading with the highest value.

\section{Bicipital skin fold}

It must be taken vertically at the midpoint (between the acromium and the olecranon) of the anterior part of the arm, on the biceps.

Tricipital skin fold

It should be taken vertically at the midpoint (between the acromion and the olecranon) of the back of the arm, on the triceps.

\section{Sub-scapular skin fold}

It should be taken obliquely towards the ribs in the region of the lower angle of the scapula. (Diagonal).

Suprailiac skin fold

It must be taken obliquely, along the ilio-suprailiac angle, it is located above the iliac crest, in the anterior axillary line. (Diagonal). 
Skin fold of the leg

It should be taken vertically, approximately $5 \mathrm{~cm}$ below the popliteal fossa. The leg should rest lightly on the ball of the foot and the opposite leg supporting the weight of the body.

\section{Anthropometric material, measurement techniques and formula for the determination of results}

For the determination of variables, we use the following instruments: Scale, Height rod, Fat calliper, Epicondylar calliper, Tape measure.

The technique for anthropometric measurements:

1. All measurements are taken on the right side of the body.

2. Locate the site (it is marked with a marker for beginners) and ensure that this is where the fingers should [poke] [penetrate] the skin.

3. Pinch skin between thumb and index finger for a fold of skin to create an elevated line in the desired direction.

4. Clamp the calliper compass perpendicular to the fold and $1 \mathrm{~cm}$ lateral or inferior to the thumb and index finger.

5. Maintain pressure with fingers and callipers and read the measurement after 2 seconds.

6. Release the callipers from the skin and ease the gentle tension so as not to damage them, then relax your thumb and index finger.

7. Take each measurement in succession / sequence and repeat. Measure the third time if it is more than $10 \%$ difference.

Formulas and procedures for obtaining the somatotype on the theoretical bases of Carter Indicators for obtaining the somatotype.

1. Determination of the endomorphic component.

Size

Three skin folds (Triccipital, Subscapular or infrascapular, Supraspinal or Suprailiac)

Determination of body fat

$X=$ Sum of the Three folds in $\mathrm{mm}$.

Formula. $X_{c}=(X) 170.18 /$ Height

Another method is:

$0.71182+0.1451\left(X_{c}\right)-0.00068\left(X_{c} 2\right)+0.0000013\left(X_{c} 3\right)$.

2. Determination of the mesomorphic component.

Height

Humerus diameter $(\mathrm{H})$

Femur diameter $(\mathrm{F})$

Contracted arm circumference (BC)

Leg circumference (CP)

Triceps crease (PT)

Leg fold (PP)

Formula

$4.50+0.858(H)+0.601(F)+0.188(B C)+0.161(P C)-0.131(E)$ 
3. Determination of the Ectomorphy component

Height

Weight

Weight index

Body mass

$\mathrm{IP}=\frac{\text { Subject's Height }}{\sqrt[3]{\text { Total Body Mass }}}$

If your $\mathbb{I P}$ is $<40.75$ then Ectomorphy $=\mathbb{I P}(0.463)-17.63$

If your IP is $>40.75$ then Ectomorphy $=\operatorname{IP}(0.732)-28.58$

4. Determination of percentage (\%) of body fat

$\% \mathrm{G}=$ Body Fat Percentage

$(X 1)=$ Triceps skin fold $(\mathrm{mm})$

$(X 2)=$ Infra-scapular skin fold $(\mathrm{mm})$

(X3) = Supra-iliac skin fold $(\mathrm{mm})$

(X4) = Bicipital skinfold (mm)

Formula

$\% \mathrm{G}=2.745+0.0008(\mathrm{X} 1)+0.002(\mathrm{X} 2)+0.637(\mathrm{X} 3)+0.809(\mathrm{X} 4)$

5. Active body mass

Formula

$\%$ G-Total Weight $=$ MCA

6. Active substance index

Formula

$\mathrm{ISA}=\frac{\text { MCA g. } \times 100}{(\text { Height })^{3}}$

7. Body weight of fat

It is determined from the rule of three, taking into account the percentage of fat and body weight. The formulations that are taken into account are those issued by Carter (1967), which are taken from the source of the Micromed software, which is used as a means to calculate the somatotype in the sample that has been chosen for the study.

\section{RESULTS}

\section{Complete analysis of the information data on somatotype.}

The results obtained in the classification of the general somatotype of the team, we will take into account that there is a tendency to endomorphic, this being $41.55 \%$ of the players, also the presence of balanced mesomorphic in two of the players and the rest is distributed ectomesomorphic, mesoendomorphic and one with a central somatotype. The results are shown in the following table below: 
Table 3. Classification of the somatotype of the Del Campo team.

\begin{tabular}{lcc}
\hline Somatotype & No of Players & $\%$ \\
\hline Classification & 5 & 41.5 \\
\hline EndoMesomorphic & 1 & 8.3 \\
EctoMesomorphic & 2 & 16.6 \\
MesoEndomorphic & 2 & 16.6 \\
Mesomorphic-Balanced & 1 & 8.3 \\
Central Somatotype & 1 & 8.3 \\
EN-ME ó ME-EN & & \\
\hline
\end{tabular}

It is important to highlight or recognize that within the interpretations that are made when determining the type of somatotype that is presented, we will take into account the existence of a predominance of fat with muscle, one of them with a good balance of height with good muscular development, and one of them with integrality in all the components; Next, the classification is presented according to the team players individually in the following table:

Table 4. Interpretation of the players taking into account the classification of the somatotype.

\begin{tabular}{lll}
\hline No & Classification & Interpretation \\
\hline 1 & Endo - Meso & Muscle With Fat \\
2 & Ecto - Meso & Muscle With Stature \\
3 & Mesom. Balanc & Muscle Predomination \\
4 & En - Me O Me - En & Combined \\
5 & Meso - Endo & Fat With Muscle \\
6 & Somat. Central & Predomination Of All \\
7 & Endo - Meso & Muscle With Fat \\
8 & Endo - Meso & Muscle With Fat \\
9 & Endo - Meso & Muscle With Fat \\
10 & Endo - Meso & Muscle With Fat \\
11 & Mesom. Balanc & Muscle Predomination \\
12 & Meso - Endo & Fat With Muscle \\
\hline
\end{tabular}

Other important results that allow a better estimate of the conditions of the team players, such as the percentage of body fat, active body fat in kilograms, active substance index, and active body mass in kilograms, as expressed in the following table attending to each of the team players.

Taking into account each of the results that are taken into account, the AKS. It is an indicator with basic similarity between the players, presenting little dispersion between the values obtained that are presented in them with an average close to 1 . What can be allowed to establish an initial per centile for the school based on this initial reference.

Regarding the percentage of GRSA, it has a close or direct proportion relationship to the values obtained in kilograms, thus recognizing the reliability of the results, which are allowed to be obtained in the MSCA.

The results obtained taking into account the characteristics of age, and the somatotype of the players, allows an estimate of the position or performance roles of the players in the team, in this sense, the table establishes the decision-making or Consideration proposal to be taken into account by the trainer. 
Table 5. On team body composition.

\begin{tabular}{lcccc}
\hline No & \% GRSA & KG GRSA & KG M.C.A. & IND. AKS \\
\hline 1 & 27.2 & 26.1 & 69.9 & 1.1 \\
2 & 12.6 & 7.6 & 52.4 & 0.9 \\
3 & 15.5 & 10.9 & 59.1 & 0.9 \\
4 & 17 & 12.2 & 59.8 & 1.0 \\
5 & 30.2 & 22.6 & 52.4 & 1.0 \\
6 & 12.4 & 8.0 & 61.3 & 1.0 \\
7 & 25.6 & 20 & 58 & 0.9 \\
8 & 17.4 & 16.5 & 78.5 & 1.0 \\
9 & 28.8 & 25.9 & 64.1 & 1.3 \\
10 & 40.4 & 43.2 & 63.8 & 1.1 \\
11 & 15.8 & 11.2 & 59.8 & 1.0 \\
12 & 38.2 & 31.3 & 50.7 & 0.9 \\
\hline & 23.4 & 19.6 & 60.8 & 1.0 \\
\hline
\end{tabular}

Legend:\% GRSA: Active Body Fat in percentage, GRSA (Kg): Active Body Fat in Kilogram, MSCA (Kg) Active Body Mass in Kilogram, IND.AKS: Active Substance Index.

Table 6. Relationship of the somatotype with the playing position.

\begin{tabular}{lllll}
\hline No & Classification & Interpretation & Actual position & Proposed position \\
\hline 1 & Endo - Meso & Muscle With Fat & Playmaker & Small Forward \\
2 & Ecto - Meso & Muscle With Stature & Shooting Guard & Small Forward) and Power \\
3 & Mesom. Balanc. & Muscle Predomination & Centre & Shoord \\
4 & En - Me O Me - En & Combined & Power Forward & Small Forward) and Power \\
5 & Meso - Endo & Fat With Muscle & Shooting Guard & Centre \\
6 & Somat. Central & Predomination Of All & Playmaker & Playmaker and Shooting Guard \\
7 & Endo - Meso & Muscle With Fat & Small Forward & Power Forward \\
8 & Endo - Meso & Muscle With Fat & Small Forward & Power Forward \\
9 & Endo- Meso & Muscle With Fat & Pivot & Power Forward \\
10 & Endo- Meso & Muscle With Fat & Power Forward & Power Forward \\
11 & Mesom. Balanc. & Muscle Predomination & Small Forward & Shooting Guard and Playmaker \\
12 & Meso-Endo & Fat With Muscle & & Centre \\
\hline
\end{tabular}

Of the relationship of the somatotype with the position they present in the team of the Colegio del Campo, we take into account that only $33.33 \%$ coincide with our recommendations for them, highlighting greater accommodation in those who have a predominance of fat with muscle, muscle with height, which from our position should have been oriented from the forward position to the pivot, although we know that other aspects are taken into account such as technical - tactical learning, time in sport, coordination levels. However, it is necessary to continue insisting on the somatotype indicator to be taken into account to determine the performance roll.

\section{DISCUSSION}

The study carried out involving twelve players from the Del Campo school basketball team, five have a percent body fat (KG GRSA) above the average that must be had at those ages, which shows an aerobic 
physical work In these players differentiated from the rest, even so, an excellent physical condition in the team stands out to start the physical-technical preparation in the different stages of the macro-cycle in general. Also, six of the players are within the range established for the indicator $\%$ fat (\% FAT) according to the sport of basketball, the remaining ones go above, but it is not significant due to the stage of preparation that the team is in. All the players show suitable values of\% MCA for the practice of basketball, taking into account the physical sports training at these ages. Eight players from the analysed team present a significant relationship according to their size. This will allow a functional technical physical work in the different planned stages within the macro cycle, allowing an ideal performance.

Despite these estimates obtained in relation to the somatotype classified in the player with the performance roll that has been adopted in the team, significant differences are shown between the current roll and a possible proposal recognizing results in already validated investigations such as that carried out by Rivera (2016). Also, other investigations that, despite having stood out in the determination of the somatotype in basketball, only commit themselves to that ideal morphology for that sport discipline, without committing to any recommendation towards the roles of performance or positions that should be proposed to the players. players.

\section{CONCLUSIONS}

The study carried out allowed us to consider that the somatotype indicator is of great importance for the determination of the performance roll in basketball, and that the Field team, with these results, acquires an initial profile that can establish initial criteria for future generations in the coming years, and to achieve better criteria for the identification and recruitment of talents according to the somatotype reference. In the same way, the monitoring, exhaustive to the physical development of the team that is kept in mind.

\section{REFERENCES}

Batista, A., Garganta, R., \& Ávila-Carvalho, L. (2019). Morphological characteristics and biological maturation of Brazilian and Portuguese gymnasts. International Journal of Morphology, 37(2), 561567. https://doi.org/10.4067/S0717-95022019000200561

Benítez, L. (2004) Clinical Nutrition and Dietetics Unit. Madrid: La Paz University Hospital.

Castro, J., \& Garatachea, N. (2015). Somatotype characteristics of the Venezuelan minor baseball player. Research Journal, 39 (85), 31-51.

Del Campo, M.A., Escortell, R. Sospedra, I., Norte, A., Martínez, A., and Martínez, J.M. (2016) Kinanthropometric characteristics in adolescent basketball players. Spanish Journal of Human Nutrition and Diet. 20 (1). https://doi.org/10.14306/renhyd.20.1.179

FIBA. (2014) Official Basketball Rules I FIBA.COM (Internet). FIBA. com. Recovered from: http://www.fiba.com/pages/eng/fc/FIBA/ruleRegu/p/openNodelDs/897/

Gilabert, A. A., Retamales, F. J., Castillo, M., \& Valenzuela, R. A. (2014). Somatotypic profile and body composition of Chilean school basketball players aged 13 to 15 years old medalists in the regional phase at the 2011 school games. Revista Ciencias de la Acción Física UCM, 1, 15.

Gryko, K., Stastny, P., \& Kopiczko, A. (2019). Can Anthropometric Variables and Maturation Capítulo III Somatotipo en jóvenes una radiografía en talentos deportivos venezolanos 180 Predict the Playing Position in Youth Basketball Players? human kinetics, 69(September). https://doi.org/10.2478/hukin

Martínez, JM, Urdampilleta A. (2012) Anthropometric measurement protocol in athletes and equations for estimating body mass. EFSports; 17 (174). 
Martínez-Sanz JM, Urdampilleta A, Guerrero J, Barrios V. (2014) Somatotype-morphology in athletes. How is it calculated? What are the international benchmarks to compare with our athletes? EFDeportes 16 (159).

Padilla, J., Lozada, J., Torres, Y., Cortina, M. and Hoyos, C. (2019). Somatotype in young people: an Xray in Venezuelan sports talents. Barinas, Venezuela: FEDEUEZ.

Porta, J, Galiano, D, Tejedo, A. (1991) Assessment of Body Composition Utopias and Realities. 114168. In: Esperanza Ros, Francisco. Manual of Kineanthropometry, Femede Monographs. 1. Ed. Spain.

Rivera, J.M. (2016) Anthropometric Properties and Somatotype of Basketball Players from Different Competition Level. International Journal of Morphology, 34(1). https://doi.org/10.4067/S0717$\underline{95022016000100026}$

Rodríguez Alonso, Carlos A. (1984) Body Composition, Somatotype and Proportionality, Methods and Procedures. Havana: Guide for Residents of the Sports Medicine Specialty.

Rodríguez, X., Castillo, O., Tejo, J., \& Rozowski, J. (2014). Somatotype of high performance athletes from Santiago, Chile. Chilean journal of nutrition, 41 (1), 29-39. https://doi.org/10.4067/S071775182014000100004

Ruderman, A., Navarro, T., Mangeaud, A., Cejas, V., \& Bajo, J. M. (2017). Somatotypes of school adolescents from Córdoba (Argentina). Argentine journal of biological anthropology, 19. https://doi.org/10.17139/raab.2017.0019.02.05

Tárrega L, Canda A. (2009) Body composition of the basketball player. In: Scientific bases for health and optimal performance in basketball. Ed. Ergón, Madrid.

Urdampilleta A, Martínez-Sanz JM, Cejuela R. (2014) Indicators of sports performance: psychological, physiological, biochemical and anthropometric aspects. EFSports; 17 (173).

Vásquez, J.P. (2000) Weight Control and Body Composition in Athletes. Regional Institute of Sports of the Miranda State.

Zatsiorski V. M. (1989) Sports Metrology. City of Havana: Editorial Pueblo y Educación.

\section{@) $\Theta \Theta \Theta$}

This work is licensed under a Attribution-NonCommercial-NoDerivatives 4.0 International (CC BY-NC-ND 4.0). 